\title{
Bronsted acid-functionalized choline chloride-butane sultone for the catalytic decomposition of cumene hydroperoxide to phenol
}

\author{
M P PADMA PRIYA and G R RAJARAJESWARI* \\ Department of Chemistry, College of Engineering, Guindy, Anna University, Chennai, Tamilnadu 600025 , \\ India \\ E-mail: gr.rajarajeswari@gmail.com
}

MS received 1 January 2018; revised 25 February 2018; accepted 28 February 2018; published online 21 March 2018

\begin{abstract}
Choline chloride and 1,4-butane sultone were combined to obtain a sulphonic acid-functionalized ionic liquid. The structural properties of the ionic liquid were evaluated with AT-IR, NMR, mass and elemental analysis. The Bronsted acidity of the ionic liquid was confirmed from the AT-IR analysis of pyridine-adsorbed samples. The catalytic activity of the ionic liquid was studied for the preparation of phenol from cumene hydroperoxide by Hock process. Various reaction parameters were optimized and kinetics of the reaction was evaluated. This Bronsted acidic choline chloride-butane sultone-based ionic liquid was highly selective towards the conversion of cumene hydroperoxide to phenol. Ease of use and recovery, low environmental impact, and effective reduction of activation energy make it a potential candidate for industrial production of phenol.
\end{abstract}

Keywords. Choline chloride; 1,4 butane sultone; ionic liquid; phenol; hock process.

\section{Introduction}

Environmentally benign industrial manufacture of phenol through decomposition of cumene hydroperoxide (CHP) utilizes a wide range of heterogeneous catalysts that include, rhenium compounds, montmorillonite clays, heteropolyacids supported on resins, nanocrystalline clays, and hydrogen fluoride on titania. ${ }^{1-5}$ Both Bronsted and Lewis acidic catalytic systems have proven to be successful for the synthesis of phenols from CHP. Barton et al., showed that various copper and iron salts served as good catalysts for the preparation of phenol from CHP. ${ }^{6}$ Cesium substituted heteropolyacids on clays carrying high Bronsted acidity has been reported by Yadav et al., for selective decomposition of CHP. ${ }^{7}$ Beta-zeolites and their metallosilicate analogues, exhibiting strong Bronsted acidity, were reported to be successful for phenol preparation by Sasidharan et al. ${ }^{8}$ Rosilda Selvin et al., reported that zinc chloride impregnated on Montmorillonite K10, and dodecatungstophosphoric acid impregnated on titania, silica and MCM-41 supports, favoured the decomposition of CHP to phenol. ${ }^{9}$
In recent times, ionic liquids are being explored as catalysts for solvent-free and green synthesis of organic chemicals. Many ionic liquids based on pyridinium, phosphonium, quaternary ammonium, imidazolium cations have been explored for various organic reactions. Thermal stability, low vapour pressure, high polarity, non-toxicity, cost-effectiveness, and easy recovery are some of the attractive advantages of ionic liquids. Amarasekara reviewed various types of Bronsted and Lewis acidic catalytic systems as successful catalysts for a wide number of organic reactions such as esterifications, saponifications, acetalizations, heterocyclic synthesis and polymerization reactions. ${ }^{10}$ According to Deng et al., ionic liquids play a vital role in many fields such as biomass conversion, catalytic production of fine chemicals, supported ionic liquid catalysis and Friedal-Crafts reactions. ${ }^{11}$ Even though ionic liquids were found to be suitable alternate for volatile organic solvents, they are now explored successfully in the areas of catalysis, electrochemistry, spectroscopy and material science by Rajni Ratti. ${ }^{12}$ Choline chloride is a quaternary ammonium salt, which, in combination with proton donors such as urea, ethylene glycol, and

\footnotetext{
*For correspondence

Electronic supplementary material: The online version of this article (https://doi.org/10.1007/s12039-018-1445-0) contains supplementary material, which is available to authorized users.
} 
carboxylic acids, forms Bronsted acidic ionic liquids. ${ }^{13}$ When combined with metal salts, Lewis acidic ionic liquids of choline chloride can be obtained. ${ }^{14}$ These Bronsted and Lewis acidic systems of choline chloride have been effectively applied for many organic transformations such as Fischer-indole synthesis, metal coatings, Knoevenagel reactions, etc. ${ }^{15-18}$

Ionic liquid systems are yet to be explored for the synthesis of phenol from CHP. Hence, the formulation of choline chloride-based Bronsted acid ionic liquid for the decomposition of CHP was adopted as a premise of this study. 1,4-butane sultone, which is a cyclic sulfonate ester with $-\mathrm{S}-\mathrm{O}$ linkage, was chosen to be combined with choline chloride. The objective was to effect ring opening of electrophilic 1,4-butane sultone with the nucleophilic choline chloride to form a zwitter ion, which can be further converted to sulphonic acidfunctionalized ionic liquid.

\section{Experimental}

\subsection{Materials}

Choline chloride, cumene, cumene hydroperoxide (80\%) and 1,4-butane sultone were purchased from Alfa aeser. The chemicals were used as received without further purification.

\subsection{Instruments}

Elemental analysis data were recorded on Perkin Elmer CHN2400 series analyser. The analysis of sulphur was performed by Perkin Elmer Optima 5300 DV ICP-OES analyser. ATIR of the synthesized ionic liquid was recorded on Perkin Elmer Spectrophotometer. The samples were scanned directly in the range of $4000-400 \mathrm{~cm}^{-1}$. NMR studies for the ionic liquid were performed on Bruker Avance $400 \mathrm{MHz}$ NMR Spectrometer using deuterated chloroform $\left(\mathrm{CDCl}_{3}\right)$ as solvent and Tetramethylsilane (TMS) as an internal standard. Electrospray Ionisation mass spectra of the ionic liquid were recorded on High resolution Q-Tof Mass Spectrometer. Gas chromatography of the samples was performed on Agilent $6890 \mathrm{~N}$ using HP5 column ( $30 \mathrm{~m} \times 0.32 \mathrm{~mm} \times 0.25 \mu \mathrm{m})$ and FID detector.

\subsection{Preparation of the ionic liquid}

Choline chloride $(0.01 \mathrm{M})$ and 1,4-butane sultone $(0.01 \mathrm{M})$ were mixed in a $100 \mathrm{~mL}$ RB flask, fitted with a condenser. The RB flask was immersed in a thermostatic oil bath placed on a magnetic stirrer. The temperature was maintained at 80 to $90^{\circ} \mathrm{C}$ and the contents were stirred for $24 \mathrm{~h}$. After $24 \mathrm{~h}$, a white solid zwitter ion was obtained (CCBU zwitter ion). Stoichiometric amount of concentrated sulphuric acid was added to the resultant zwitter ion and the reaction mixture was subjected to heating at $60^{\circ} \mathrm{C}$ for $4 \mathrm{~h}$. A colourless and homogeneous viscous liquid was obtained in a quantitative yield
(CCBU ionic liquid). In the above step involving addition of sulphuric acid to CCBU zwitter ion, a separate round-bottom flask containing water was connected to the main RB flask containing reaction mixture. Throughout the course of reaction, the $\mathrm{HCl}$ formed was dissolved in water. The evolved $\mathrm{HCl}$ dissolved in water was confirmed by formation of white precipitate with $\mathrm{AgNO}_{3}$ solution. The complete evolution of $\mathrm{HCl}$ was confirmed by changing water at regular intervals of time. After $4 \mathrm{~h}$, the water was inert to $\mathrm{AgNO}_{3}$ test. The $\mathrm{HCl}$ collected in water was evaluated stoichiometrically by means of standard $\mathrm{NaOH}$ titration.

2.3a Spectral data of (I) CCBU zwitter ion: $\mathrm{C}_{9} \mathrm{H}_{22} \mathrm{O}_{4}$ CINS Anal. Found: C, 37.3; H, 9.11; N, 5.18; S, 10.57\%; Calc.: C, 39.19; H, 8.04; N, 5.08; S, 11.63\%. AT-IR data $\left(\mathrm{cm}^{-1}\right)$ : 3307, 2950, 1473, 1163, 1023, 952, 777, 707, NMR data: ${ }^{1} \mathrm{H}$ NMR (400 MHz, $\mathrm{CDCl}_{3}$, TMS) $\delta 4.25(\mathrm{~s}, 1 \mathrm{H}) ; 4.09$ (t, 2H); 3.70 (t, 2H); 3.58 (t, 2H); 3.34 (s, 9H); 2.83 (t, 2H); $1.93(\mathrm{~m}, 4 \mathrm{H}) .{ }^{13} \mathrm{C} \mathrm{NMR}\left(400 \mathrm{MHz}, \mathrm{CDCl}_{3}\right.$, TMS) $\delta 22.81$; $31.51 ; 44.89 ; 50.95 ; 54.47 ; 56.39 ; 67.92$. M cation, $104.1 ; \mathrm{M}$ anion, 171.

2.3b Spectral data of (II) CCBU ionic liquid: $\mathrm{C}_{9} \mathrm{H}_{23} \mathrm{O}_{8} \mathrm{NS}_{2}$ Anal. Found: C, 28.48; H, 7.41; N, 3.88; S, 17.68\% Calc.: C, 32.04; H, 6.87; N, 4.15; S, 19.01\%. ATIR data $\left(\mathrm{cm}^{-1}\right)$ : $3405,2955,1479,1149,1037,952,862,741$. NMR data: ${ }^{1} \mathrm{H}$ NMR $\left(400 \mathrm{MHz}, \mathrm{CDCl}_{3}\right.$, TMS $\delta 4.57(\mathrm{t}, 2 \mathrm{H})$; $4.17(\mathrm{~s}, 1 \mathrm{H}) ; 3.70$ (t, 2H); 3.59 (t, 2H); $3.26(\mathrm{~s}, 9 \mathrm{H}) ; 2.26(\mathrm{t}$, $2 \mathrm{H}) ; 1.97(\mathrm{~m}, 4 \mathrm{H}) .{ }^{13} \mathrm{C}$ NMR (400 MHz, $\left.\mathrm{CDCl}_{3}, \mathrm{TMS}\right) \delta$ : $21.41 ; 30.77 ; 44.17 ; 48.28 ; 50.95 ; 54.22 ; 74.04$. M cation, 104.1, M anion, 233.4.

\subsection{Decomposition of cumene hydroperoxide}

A $20 \%$ solution of CHP in cumene ( $2 \mathrm{~mL}$ of CHP in 10 $\mathrm{mL}$ cumene) was taken along with $0.2 \mathrm{~g}$ of ionic liquid in a $100 \mathrm{~mL}$ round-bottom flask. The mixture was placed on a thermostatic oil bath and stirred using a magnetic stirrer for $30 \mathrm{~min}$. The temperature was maintained at $50^{\circ} \mathrm{C}$. The progress of the reaction was monitored by withdrawing aliquots of the reaction mixture at regular intervals and subjecting them to gas chromatographic analysis.

\section{Results and Discussion}

When an equimolar amount of 1,4-butane sultone was added gradually in smaller portions to choline chloride, the chloride anion of choline chloride took active part as a nucleophile in the ring opening and effected a complete conversion under mild reaction conditions in $24 \mathrm{~h}$. The choline chloride-butane sultone CCBU zwitter ion (with chloroalkylsulphonate anion) was free from chloride impurities, as confirmed through $\mathrm{AgNO}_{3}$ titration. ${ }^{19}$ The presence of the two ionic moieties in the zwitter ion was evident from the AT-IR spectral studies (see Supplementary Information for AT-IR spectra). The addition of concentrated sulphuric acid to the zwitter ion 
resulted in a thick, highly viscous and colourless $-\mathrm{SO}_{3} \mathrm{H}$ functionalized ionic liquid. This conversion could be explained by the observed shift in the AT-IR peak for $\mathrm{SO}_{3}^{-}$from $1023 \mathrm{~cm}^{-1}$ in zwitter ion to $1037 \mathrm{~cm}^{-1}$, due to the formation of $-\mathrm{SO}_{3} \mathrm{H}$ group in ionic liquid.

The proposed scheme for the formation of the zwitter ion and the ionic liquid is outlined in Scheme 1.

NMR data confirmed the structures of CCBU zwitter ion and ionic liquid formed in the above scheme (see Supplementary Information for NMR data). ${ }^{1} \mathrm{H}$ NMR spectrum of CCBU zwitter ion confirmed the ring opening of 1,4-butane sultone by choline chloride.

\subsection{Acidity of CCBU ionic liquid}

Pyridine, which was used as a probe molecule, was adsorbed onto the CCBU ionic liquid and the type of acidity of the latter was analysed from the AT-IR spectral data. Generally, neat pyridine exhibits two well-resolved peaks at $1437 \mathrm{~cm}^{-1}$ and $1581 \mathrm{~cm}^{-1}$. Interaction of pyridine with Lewis and Bronsted acid sites leads to specific shift in the absorption bands. While the presence of Lewis acid sites effect a shift in the range of 1445$1460 \mathrm{~cm}^{-1}$ and $1602-1640 \mathrm{~cm}^{-1}$, Bronsted acid sites bring in a shift of the characteristic pyridine bands in the range of $1530-1550 \mathrm{~cm}^{-1}$ and $1631-1640 \mathrm{~cm}^{-1} .^{20}$ In the present case, the characteristic pyridine bands in IR were shifted to $1636 \mathrm{~cm}^{-1}$ and $1537 \mathrm{~cm}^{-1}$, respectively, thus, confirming the occurrence of only Bronsted acid sites in the CCBU ionic liquid (Figure 1). The acidity determination studies also consolidated the creation of Bronsted acid sites proposed in Scheme 1.

\subsection{Effect of reaction parameters on decomposition of $\mathrm{CHP}$}

The decomposition of CHP was carried out in the presence of CCBU ionic liquid. In all the experimental runs, a $100 \%$ conversion of CHP was achieved within $30 \mathrm{~min}$ and equimolar amounts of phenol and acetone
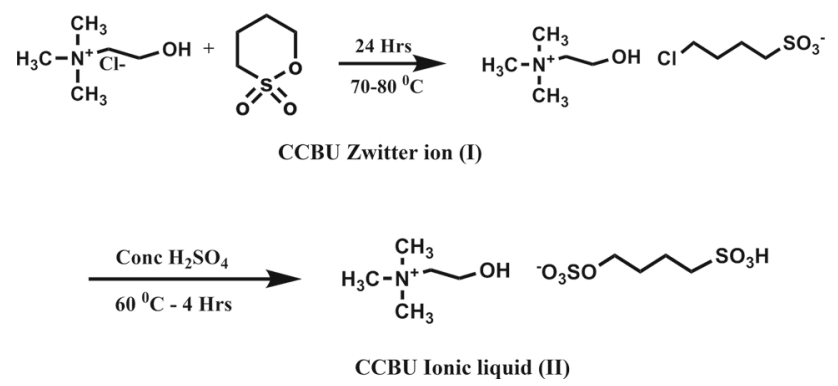

Scheme 1. Synthesis of choline chloride-butane sultone $(\mathrm{CCBU})$ ionic liquid.

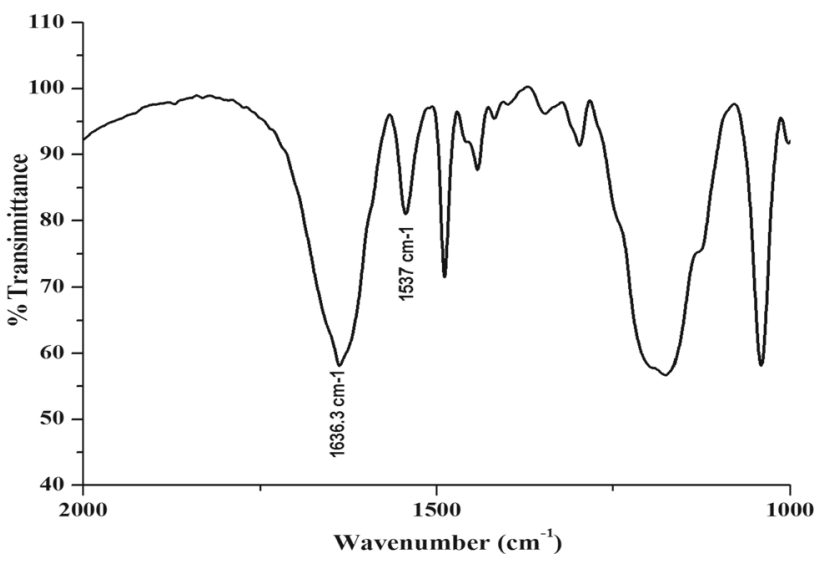

Figure 1. Pyridine - IR spectrum of ionic liquid.

were obtained with $100 \%$ selectivity (Refer Supplementary Information for chromatogram), without any other side products. The reaction parameters were optimized by varying the initial concentration of CHP, amount of CCBU ionic liquid and the reaction temperature. The percentage conversion of CHP was about $89 \pm 5 \%$, when its initial concentration was varied in the range of 6.5 to $32.8 \mathrm{mM}$ in cumene (Figure 2a). The percentage conversion was found to decrease slightly with an increase in the concentration of CHP and hence a 13.8 $\mathrm{mM}$ of CHP in $10 \mathrm{~mL}$ cumene was optimal under the present reaction conditions. The effect of the weight of ionic liquid on the decomposition of CHP was studied in the range of $0.1 \mathrm{~g}$ to $0.4 \mathrm{~g}$ at $50{ }^{\circ} \mathrm{C}$ (Figure $2 \mathrm{~b}$ ). The rate of decomposition of CHP increased slightly with an increase in catalyst loading. But, the increment in rate was negligible beyond $0.2 \mathrm{~g}$ of ionic liquid in the reaction mixture. The variation of reaction temperature exhibited a moderate influence on the conversion of CHP within a temperature range of $30^{\circ} \mathrm{C}$ to $60^{\circ} \mathrm{C}$ (Figure 2c). Generally, an increase in the temperature favored the decomposition of CHP, but the effect was less pronounced beyond $50^{\circ} \mathrm{C}$.

The reaction followed first order kinetics with respect to CHP, as confirmed by the plots of $\ln [\mathrm{a} /(\mathrm{a}-\mathrm{x})]$ \{ $\mathrm{a}$ and $\mathrm{x}$ are the concentrations of CHP and phenol, respectively) with respect to time at different temperatures (Figure 2d). The rate constant of the reaction (k) was calculated from the slope of plot (Figure $2 \mathrm{~d}$ ) or by the formula, $\mathrm{k}=(1 / \mathrm{t}) \ln [\mathrm{a} /(\mathrm{a}-\mathrm{x})]$. The activation energy for the CCBU ionic liquid-catalyzed decomposition of CHP was calculated to be $16.6 \mathrm{kcal} / \mathrm{mole}$, from the plot of $\ln \mathrm{k}$ vs $1 / \mathrm{T}$ (Figure 2e).

3.2a Reaction mechanism for decomposition of CHP: Scheme 2 outlines an ionic decomposition mechanism proposed for the decomposition of CHP by CCBU 
a

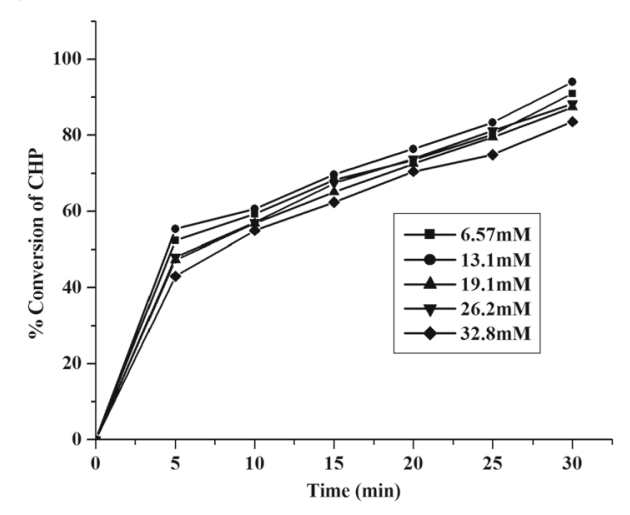

C

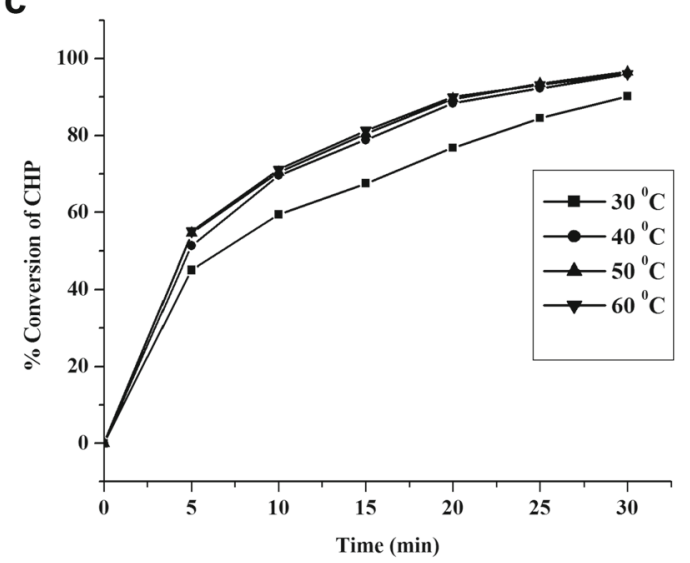

b

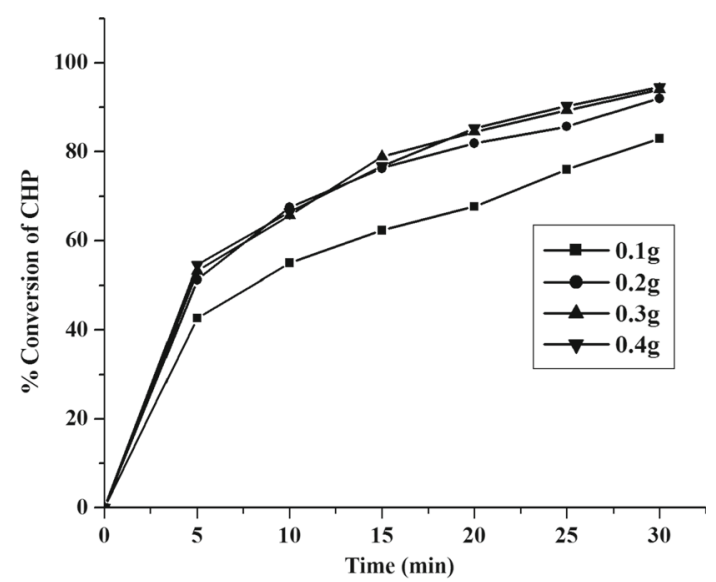

d

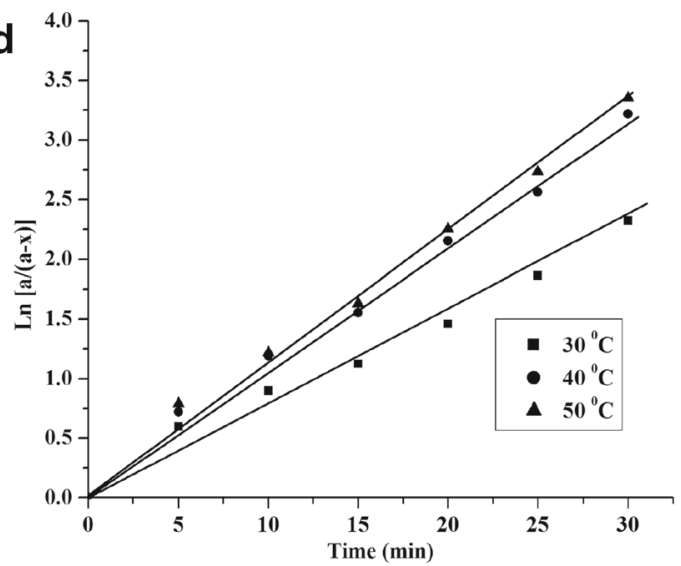

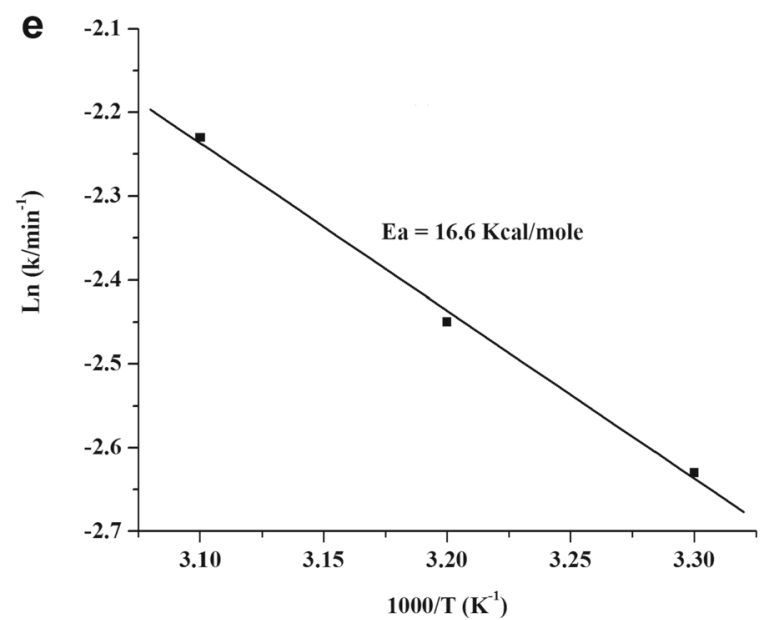

Figure 2. Plots for the decomposition of CHP to phenol in presence of CCBU ionic liquid: Effect of concentration of CHP, (b) Effect of catalyst loading, (c) Effect of Temperature, (d) Kinetics Plot and (e) Arrhenius plot.

ionic liquid, analogous to that reported by Seubold and Vaughan. ${ }^{21}$

The $\mathrm{CCBU}$ ionic liquid, being $-\mathrm{SO}_{3} \mathrm{H}$ functionalized, was strongly Bronsted acidic and hence protons were released for the formation of protonated peroxide [II]. Loss of water from [II] resulted in a highly unstable intermediate [III]. Intermediate [III] underwent a $[1,2]$ rearrangement through the migration of phenol group to electron deficient oxygen to satisfy its octet configuration and yielded a carbocation [IV]. The carbocation [IV] reacted with the liberated water molecule and a hemiacetal [V] was obtained. This hemiacetal fragmented into phenol and acetone, with the regeneration of ionic liquid. Thus, the decomposition of CHP 

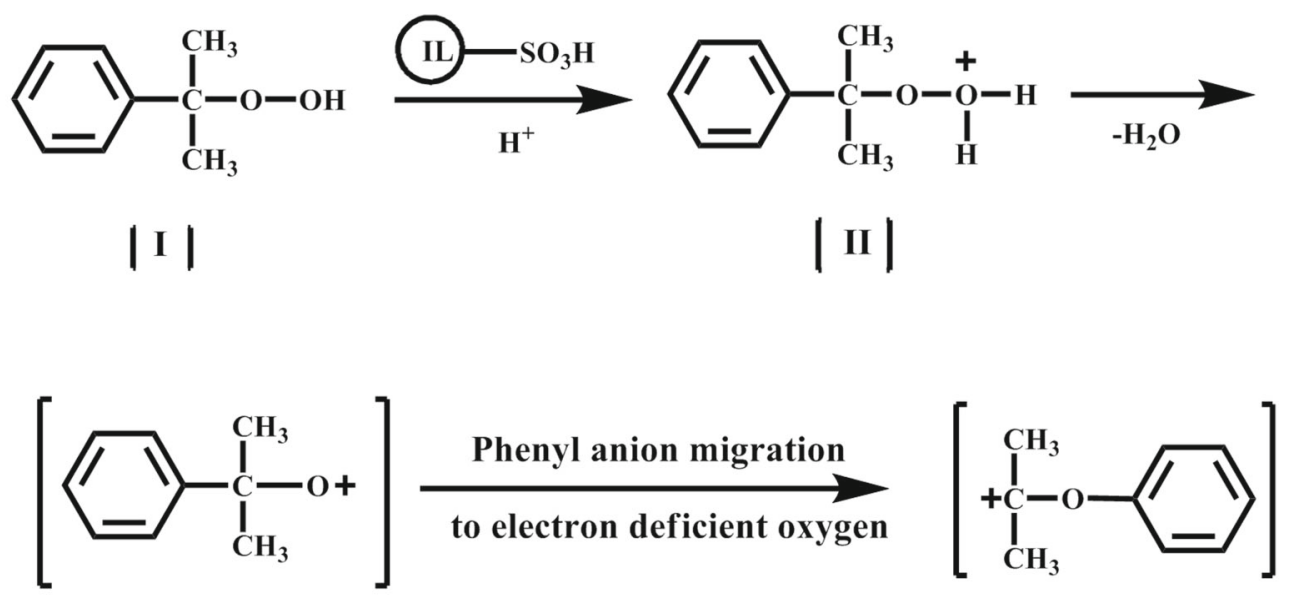

|III |

| IV|

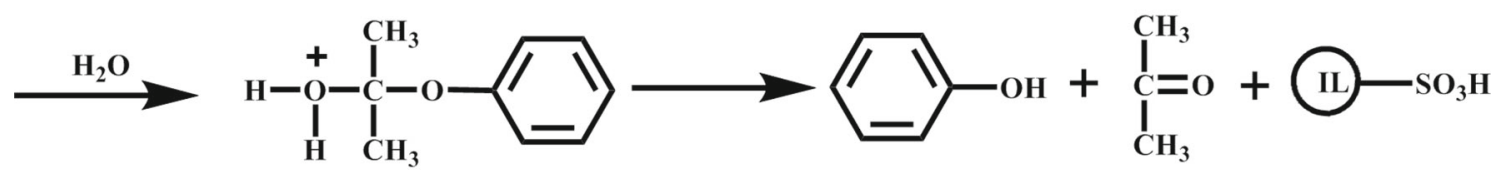

$|v| \quad$ Phenol Acetone

Scheme 2. Proposed pathway for the decomposition of CHP into phenol.

Table 1. Percentage yield of phenol by various catalytic systems.

\begin{tabular}{|c|c|c|c|c|}
\hline Sl. No & Catalytic system used & Percentage Yield (\%) & $\begin{array}{l}\text { Reported Acti- } \\
\text { vation energy } \\
(\mathrm{kcal} / \mathrm{mol})\end{array}$ & Reference \\
\hline 1 & $\begin{array}{l}\mathrm{ZnCl}_{2} \text { on various } \\
\text { supports }\end{array}$ & $\sim 90$ & 23.9 & Rosilda Selvin et al. ${ }^{9}$ \\
\hline 2 & $\begin{array}{l}\text { Heteropoly acid } \\
\text { supported on K-10 } \\
\text { clay }\end{array}$ & $\sim 90$ & 19.4 & Yadav et al. ${ }^{7}$ \\
\hline 3 & Zeolites & $\sim 88$ & - & Sasidharan et al. ${ }^{8}$ \\
\hline 4 & $\begin{array}{l}\text { Aqueous acetic acid in } \\
\text { para-toluene } \\
\text { sulphonic acid }\end{array}$ & $\sim 92$ & 21.3 & Seubold et al. ${ }^{21}$ \\
\hline 5 & $\begin{array}{l}\text { Copper \& Iron salts in } \\
\text { solvents }\end{array}$ & $\sim 92$ & - & Barton et al. ${ }^{6}$ \\
\hline 6 & CCBU Ionic liquid & $\sim 90$ & 16.6 & This study \\
\hline
\end{tabular}

could be proposed to proceed through Bronsted acid catalysed pathway.

The percentage yield and activation energy reported by various catalytic systems are presented in Table 1 .

In comparison to the reports, the CCBU ionic liquid synthesized in the present study exhibited a reduction of more than $14 \%$ of activation energy (16.6 $\mathrm{kcal} / \mathrm{mol}$ ). This enhanced catalytic efficiency attested the superiority of the choline chloride-butane sultone ionic liquid for decomposition of cumene hydroperoxide.

When compared to other Bronsted acids such as clay supported heteropoly acids, zeolites and supported metal salts, this CCBU ionic liquid offered various advantages such as simple synthetic procedure, water solubility, eco-friendly nature, immiscibility with 


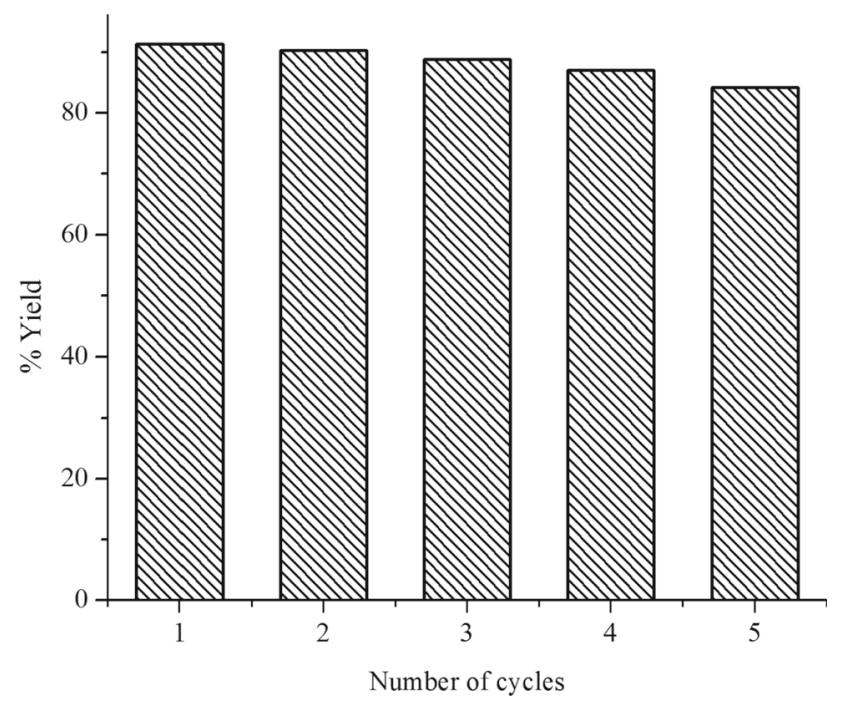

Figure 3. Recovery and reusability of CCBU ionic liquid.

reaction phase, reduced activation energy and reproducibility.

\subsection{Recovery and reusability of CCBU ionic liquid}

Recovery and reusability of ionic liquid are two important aspects for its large scale catalytic applications. After the completion of the first experimental run of CHP decomposition, the CCBU ionic liquid was extracted with a mixture of diethyl ether and ethyl acetate (1:1). It was recovered successfully on evaporation of ether phase and vacuum drying at $70^{\circ} \mathrm{C}$ for $1 \mathrm{~h}$. The reusability was examined for five cycles. The yield of phenol was found to have decreased by about $7 \%$ after five cycles of reuse of the catalyst (Figure 3 ).

\section{Conclusions}

The CCBU ionic liquid synthesized and reported in this study is proposed to catalyze the decomposition of CHP to phenol through the Bronsted acid attack on the cumene hydroperoxide. Low environmental impact, operational simplicity, water resistance, recovery and reusability without significant loss in its activity, combined with a high percentage of conversion of CHP, make the choline chloride-butane sultone ionic liquid as a promising alternative to conventional solid acid catalysts for the industrially significant Hock process for phenol production.

\section{Supplementary Information (SI)}

AT-IR, ${ }^{1} \mathrm{H}$ and ${ }^{13} \mathrm{C}$ NMR spectra of CCBU zwitter ion (I) and ionic liquid (II) (Figures S1-S6) and Gas Chromatogram of reaction mixture (Figure S7) are available in Supplementary Information at www.ias.ac.in/chemsci.

\section{Acknowledgements}

The authors thank the Department of Science and Technology and University Grants Commission, Government of India for DST-FIST and UGC-SAP-sponsored analytical instrumentation facilities at the Department of Chemistry, Anna University, Chennai. MPPP is thankful to Anna University, Chennai for providing financial aid through Anna Centenary Research Fellowship.

\section{References}

1. Wu C Y, Pretzer W R and Kobylinski T P 1979 Decomposition of cumene hydroperoxide with a heterogeneous catalyst U.S. Patent No. 4, 173, 587

2. Knifton J F 1989 Method for production of phenol/acetone from cumene hydroperoxide U.S. Patent No. 4, 870, 217

3. Knifton J F and Sanderson J R 1990 Method for production of phenol/acetone from cumene hydroperoxide U.S. Patent No. 4, 898, 995

4. Kumar K P, Selvin R, Kumari P, Roselin L S, Arul N S and Bououdina M 2010 Selective decomposition of cumene hydroperoxide into phenol and acetone over nanocrystalline ZSM-5 Int. J. Mater. Eng. Innov. 1417

5. Knifton J F and Grice N J 1989 Method for production of phenol/acetone from cumene hydroperoxide U.S. Patent No. 4, 876, 397

6. Barton D H R and Delanghe N C 1997 New Catalysts for the conversion of cumene hydroperoxide into phenol Tetrahedron Lett. 386351

7. Yadav G D and Asthana N S 2003 Selective decomposition of cumene hydroperoxide into phenol and acetone by a novel cesium substituted heteropolyacid on clay Appl. Catal. A 244341

8. Sasidharan M and Kumar R 1997 Zeolite-catalysed selective decomposition of cumene Hydroperoxide into phenol and acetone J. Chem. Res. 52

9. Selvin R, Rajarajeswari G R, Roselin L S, Sadasivam V, Sivasankar B and Rengaraj K 2001 Catalytic decomposition of cumene hydroperoxide into phenol and acetone Appl. Catal. A 219125

10. Amarasekara A S 2016 Acidic ionic liquids Chem. Rev. 1166133

11. Zhang Q, Zhang S and Deng Y 2011 Recent advances in ionic liquid catalysis Green Chem. 132619

12. Ratti R 2014 Ionic liquids: synthesis and applications in catalysis Adv. Chem. 1

13. Rengstl D, Fischer V and Kunz W 2014 Low-melting mixtures based on choline ionic liquids PCCP 1622815

14. Harjani J R, Nara S J and Salunkhe M M 2002 Lewis acidic ionic liquids for the synthesis of electrophilic alkenes via the Knoevenagel condensation Tetrahedron Lett. 431127 
15. Haerens K, Matthijs E, Chmielarz A and Bruggen B V 2009 The use of ionic liquids based on choline chloride for metal deposition: A green alternative? J. Environ. Manag. 903245

16. Morales R C, Tambyrajah V, Jenkins P R, Davies D L and Abbott A P 2004 The regiospecific Fischer indole reaction in choline chloride $2 \mathrm{ZnCl}_{2}$ with product isolation by direct sublimation from the ionic liquid Chem. Commun. 158

17. Harishkumar H N, Mahadevan K M, Kiran Kumar H C and Satyanarayan N D 2011 A facile, choline chloride/urea catalyzed solid phase synthesis of coumarins via Knoevenagel condensation Org. Commun. 426
18. Florea A, Petica A, Anicai L and Visan T 2010 Preliminary studies of silver coatings formation from choline chloride based ionic liquids UPB Sci. Bull. 72115

19. Paape N, Wei W, Bosmann A, Kolbeck C, Maier F, Steinruck H P, Wasserscheid P and Schulz P S 2008 Chloroalkylsulfonate ionic liquids by ring opening of sultones with organic chloride salts Chem. Commun. 3867

20. An H, Kang L, Gao W, Zhao X and Wang Y 2013 Synthesis and characterization of novel Brønsted-Lewis acidic ionic liquids Green Sustain. Chem. 332

21. Seubold F H and Vaughan W E 1953 Acid-catalyzed decomposition of cumene hydroperoxide J. Am. Chem Soc. 753790 